\title{
ON THE INCREASED URIC ACID CLEARANCE FOLLOWING THE INTRAVENOUS INFUSION OF HYPERTONIC GLUCOSE SOLUTIONS ${ }^{1}$
}

\author{
By ROY W. BONSNES AND ETHEL S. DANA \\ (From the Department of Obstetrics and Gynecology, Cornell University Medical College, and \\ The New York Hospital, New York City)
}

(Received for publication November 3, 1945)

We had observed previously that the uric acid clearance was not altered by the injection of $50 \mathrm{ml}$. of 50 per cent glucose (1). We concluded, therefore, that the active and maximal reabsorption of glucose had no effect upon the simultaneous reabsorption of uric acid. On the other hand, Talbot (2) has reported an increase in the amount of uric acid excreted when the blood glucose is maintained at relatively high levels (400 mgm. per cent) by a continuous infusion of glucose. In view of this apparent contradiction we have determined the uric acid and urea clearances during the continuous infusion of glucose. The results obtained confirm the correctness at least in part of both reports.

\section{EXPERIMENTAL PROCEDURE}

The subjects were normal women in the early puerperium. They were in the postabsorptive state. The procedure used is presented in Figure 1.

The glucose solutions administered intravenously were commercial preparations of 20 and 50 per cent glucose in distilled water.

Blood samples were obtained by venipuncture, usually from the cubital vein. The bladder was emptied by air injection and washing with saline whenever necessary.

Plasma and urine uric acid were determined by the Folin 1922 method slightly modified as previously described (1). Blood and urine urea were determined by the method of Van Slyke and Kugel (3). Blood sugar was determined by the Benedict blood sugar method (4). Urinary sugar was detected or quantitatively determined by the respective Benedict qualitative (5) or quantitative (6) methods.

The rate of creatinine excretion was used to check the completeness of the urine collections. Creatinine was determined by the Jaffe reaction by a procedure described elsewhere (7).

\section{RESULTS}

The rate of uric acid excretion and therefore the uric acid clearance is markedly increased when

1 This study was aided by a grant from the John and Mary R. Markle Foundation. the blood glucose is maintained well above normal physiological values. The rate of excretion seems to be a function of the blood sugar level.

At the same time, the urea clearance and the rate of the creatinine excretion increase only slightly. This increase is of the same order of magnitude in both instances, and averages about 1.25 times the values observed during the control periods.

Representative results of a single experiment are presented in Table I. It will be noted that the uric acid clearances observed during the infusion of the glucose averaged 2.54 times greater than the clearances observed during the control periods. The urea clearances, however, averaged only 1.08 times greater during the infusion than during the control periods. An appreciable decrease in the plasma uric acid was observed only in this one instance. The decrease is not of sufficient magnitude, however, to account for the observed change in clearance.

The results obtained on the four subjects studied are given in Table II. The data are expressed as a ratio of the average values observed during the experimental periods to those obtained during the control periods. In each case the creatinine excretion and the urea clearance increase by approximately the same amount. The increase in the uric acid clearance, however, is signficantly greater than the increase in the other two functions measured.

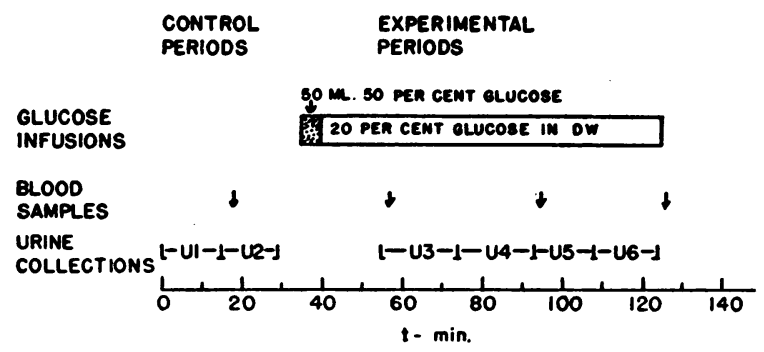

Fig. 1. Experimental Procedure 
URIC ACID CLEARANCE FOLLOWING HYPERTONIC GLUCOSE

TABLE I

Summary of data from subject $O . V$. Surface area $=1.85$ sq. m.

\begin{tabular}{|c|c|c|c|c|c|c|c|c|c|}
\hline \multirow[b]{2}{*}{ Period } & \multicolumn{3}{|c|}{ Blood } & \multicolumn{4}{|c|}{ Urine } & \multicolumn{2}{|c|}{ Clearance } \\
\hline & Glucose & Urea & Uric acid & Glucose & Urea & Uric acid & Flow & Urea & Uric acid \\
\hline $\begin{array}{c}1 \\
2 \\
\text { Ave. }\end{array}$ & $\begin{array}{c}\underset{\text { per cent }}{\text { mgm. }} \\
77 \\
77 \\
77\end{array}$ & $\begin{array}{c}\underset{\text { per cent }}{\operatorname{mgm} .} \\
12.1 \\
12.1 \\
12.1\end{array}$ & $\begin{array}{c}\underset{\text { mgm. }}{\text { per cent }} \\
7.1 \\
6.9 \\
7.0\end{array}$ & $\begin{array}{c}\text { grams } \\
\text { per cent } \\
0 \\
0\end{array}$ & $\begin{array}{c}\underset{\text { mgm. }}{\text { per cent }} \\
130 \\
117\end{array}$ & $\begin{array}{c}\text { mgm. } \\
\text { per cent } \\
9.7 \\
9.2\end{array}$ & $\begin{array}{c}\text { ml. } \\
\text { per min. } \\
9.9 \\
10.4\end{array}$ & $\begin{array}{c}\text { ml. } \\
\text { per min. } \\
99 \\
93 \\
96\end{array}$ & $\begin{array}{c}\text { ml. } \\
\text { per mix. } \\
12.7 \\
13.1 \\
12.9\end{array}$ \\
\hline $\begin{array}{c}\text { Glucose } \\
\text { Administered } \\
3 \\
4 \\
5 \\
6 \\
\text { Ave. }\end{array}$ & $\begin{array}{r}400 \\
540 \\
.640 \\
690 \\
566\end{array}$ & $\begin{array}{l}12.0 \\
12.3 \\
12.9 \\
12.5 \\
12.4\end{array}$ & $\begin{array}{l}6.6 \\
6.4 \\
6.1 \\
5.7 \\
6.2\end{array}$ & $\begin{array}{l}1.5 \\
1.6 \\
1.8 \\
1.8\end{array}$ & $\begin{array}{l}62 \\
49 \\
42 \\
39\end{array}$ & $\begin{array}{l}9.1 \\
8.4 \\
6.4 \\
6.3\end{array}$ & $\begin{array}{l}26.1 \\
31.9 \\
36.2 \\
37.9\end{array}$ & $\begin{array}{r}99 \\
97 \\
112 \\
107 \\
104\end{array}$ & $\begin{array}{l}26.1 \\
31.9 \\
36.2 \\
37.9 \\
33.0\end{array}$ \\
\hline
\end{tabular}

It is probable that the factors which are operating to increase the urea clearance and the rate of creatinine excretion are also operating to increase the uric acid clearance. If it is assumed that the increase in the urea clearance and the creatinine excretion indicates an increase in the filtration rate, then part of the increase in the uric acid clearance must also be referable to this changed filtration rate. Even so, the increase in the uric acid clearance is still significantly greater than the increase in the other functions measured. It would appear, therefore, that this increase in the uric acid excretion is due not only to an alteration in the filtration rate, but also to an alteration in the tubular reabsorption of uric acid.

The maximum uric acid clearance which we have been able to obtain under these circumstances has been about one third of the normal inulin clearances. $^{2}$ To attain such values, the blood sugar levels were maintained between 600 and 1000 mgm. per cent.

\section{DISCUSSION}

These experiments show why we did not observe any changes in the uric acid excretion in the previous work (1). In those experiments the glucose was given in a single $50 \mathrm{ml}$. injection of 50 per cent glucose and the urines were then collected in three separate one-hour periods following the injection. Under such circumstances the blood sugar levels should have been high for at least 15 to 30 minutes following the administration of the glucose (8). The tubular excretory mass for glu-

2 Taken to be about $120 \mathrm{ml}$. per min. per 1.73 sq. m. cose would have been exceeded only during this time. Any alteration in the uric acid excretion due to the presence of glucose should have been seen during the first of the three periods. Since the uric acid excretion and therefore the clearance remained essentially constant under these circumstances, it was concluded that "the injection of hypertonic solutions of glucose exerted no effect upon the excretion of uric acid" (1).

This statement is still correct in part, since glucose injections or infusions affect the uric acid excretion only when the glucose level in the tubule reaches and is maintained at relatively high levels during the period of the urine collection. In other words, glucose in the kidney tubule at physiological levels (possibly with respect to both concentration and position) does not affect the uric acid reabsorption. The decrease in the rate of uric acid reabsorption occurs, then, only when the glucose in the kidney tubule is maintained at levels in excess of the ability of the tubule to reabsorb the glucose.

TABLE II

The ratio of values of the uric acid and urea clearances and the rate of creatinine excretion observed during the intravenous infusion of glucose to the values observed during the control periods

\begin{tabular}{c|c|c|c}
\hline \hline Subject & $\begin{array}{c}\text { Uric acid } \\
\text { clearance }\end{array}$ & $\begin{array}{c}\text { Urea } \\
\text { clearance }\end{array}$ & $\begin{array}{c}\text { Creatinine } \\
\text { excretion }\end{array}$ \\
\hline O.V. & 2.54 & 1.08 & 1.13 \\
M.C. & 2.08 & 1.25 & 1.25 \\
S.T. & 3.41 & 1.28 & 1.45 \\
M.E. & 2.26 & 1.21 & 1.27 \\
\hline Ave. & 2.57 & 1.25 & 1.23 \\
\hline
\end{tabular}


These data also confirm Talbot's results qualitatively but not quantitatively. He states (2) that it is possible to increase the amount of uric acid excreted by the infusion of glucose so that the uric acid clearance approaches the glomerular filtration rate. We, on the other hand, have not been able to obtain values greater than one-third of the normal inulin clearance as was indicated above. It is possible that this quantitative difference is due to a difference in the specificity of the methods used for the determination of uric acid.

These data indicate, therefore, that this effect of high tubular concentrations of glucose might be due directly to the presence of glucose which competes in some mechanism, or part of a mechanism, which is involved in the reabsorption of the uric acid. Or the effect may be due to the diuresis produced by the glucose, since the inhibition occurs only when a diuresis occurs.

However, a water diuresis does not produce such an increase in the uric acid clearance $(1,9)$ although it must be granted that urine flows as great as those produced by glucose cannot be produced readily by water alone. Moreover, there seems to be a better correlation between the blood glucose concentration and the uric acid clearance, than there is between the urine flow and the uric acid clearance. This might indicate that the inhibition of the reabsorption of the uric acid by the glucose is independent of the urine flow.

We have assumed that the observed increase in the urea clearance and the rate of creatinine excretion is due to an increase in the glomerular filtration rate. Contrariwise, Selkurt (10) has reported no increase in glomerular filtration in the dog receiving infusions of hypertonic glucose. Similarly, Klopp, Young and Taylor (11) did not observe any change in the glomerular filtration rate in man when glucose and para-aminohippuric acid at low plasma levels were infused, but they did observe an increase in glomerular filtration rate when the concentration of the para-aminohippuric acid was increased. They did not, however, try infusions of glucose.

These data do not yield any information as to the actual mechanism involved. The possible mechanisms by which such a phenomenon may occur have been discussed by Selkurt (10) who has observed that glucose at plasma levels similar to those employed in these experiments interferes with the reabsorption of ascorbic acid in the dog.

\section{SUMMARY}

The rate of uric acid excretion and therefore the uric acid clearance is markedly increased when the blood glucose is maintained well above normal physiological levels. The rate of uric acid excretion seems to be a function of the increase in the blood sugar level. With the blood sugar maintained at an average value of $499 \mathrm{mgm}$. per cent, the average uric acid clearance increased in four patients 2.57 times the control clearances. At the same time the urea clearance and the rate of creatinine excretion increased only 1.25 times the values observed during the control periods. Some of the factors which may be operating to produce these results are discussed.

We wish to acknowledge with thanks the technical assistance of Mrs. Eleanor M. Brew and Miss LucyJane Ford.

\section{BIBLIOGRAPHY}

1. Bonsnes, R. W., Dill, L. V., and Dana, E. S., The effect of diodrast on the normal uric acid clearance. J. Clin. Invest., 1944, 23, 776.

2. Talbot, J. H., Gout. Oxford Medicine, vol. IV, part I, chapter IV, Oxford University Press, New York, 1943.

3. Van Slyke, D. D., and Kugel, V. H., Improvements in manometric micro-Kjeldahl and blood urea methods. J. Biol. Chem., 1933, 102, 489.

4. Benedict, S. R., The determination of blood sugar. J. Biol. Chem., 1928, 76, 457.

5. Benedict, S. R., A reagent for the detection of reducing sugars. J. Biol. Chem., 1908-09, 5, 485.

6. Benedict, S. R., The detection and estimation of glucose in urine. J. A. M. A., 1911, 57, 1193.

7. Bonsnes, R. W., and Taussky, H. H., On the colorimetric determination of creatinine by the Jaffe reaction. J. Biol. Chem., 1945, 158, 581.

8. Lozner, E. L., Winkler, A. W., Taylor, F. H..L., and Peters, J. P., The intravenous glucose tolerance test. J. Clin. Invest., 1941, 20, 507.

9. Brфchner-Mortensen, K., Uric Acid in Blood and Urine. Levin and Munksgaard, Copenhagen, 1937.

10. Selkurt, E. E., The influence of glucose renal tubular reabsorption and p-aminohippuric acid tubular excretion on the simultaneous clearance of ascorbic acid. Am. J. Physiol., 1944, 142, 182.

11. Klopp, C., Young, N. F., and Taylor, H. C., Jr., Probable errors in the simultaneous measurement of separate kidney functions. J. Clin. Invest., 1945, 24, 117. 